\title{
Trail-following behaviour in two Aphaenogaster ants
}

\author{
Alain Lenoir • Amélie Benoist • Abraham Hefetz • \\ Wittko Francke · Xim Cerdá · Raphaël Boulay
}

\begin{abstract}
In the course of our studies on the chemical ecology of the widely distributed Mediterranean ant Aphaenogaster senilis, we found that trail following is triggered by extracts of the poison gland and Dufour's gland. To assess the specificity of the trail pheromone, we examined whether a cross-reaction exists between trails of A. senilis and the closely related species A. iberica. Specificity seemed to differ amongst these two species, because workers of A. senilis did not follow trails of A. iberica, whereas the latter followed trails made by both species. Chemical analyses of the glandular contents reveal that Dufour's glands of both species contain mainly alkanes and alkenes exhibiting species-specific profiles. However, differences in the poison gland content of the two species were dramatic, with A. senilis showing high amounts of alkaloids that were completely absent in A. iberica.
\end{abstract}

A. Lenoir (\&) · A. Benoist

IRBI, UMR CNRS 6035, Université François Rabelais, Parc de Grandmont, 37200 Tours, France

e-mail: alain.lenoir@univ-tours.fr

\section{A. Hefetz}

Department of Zoology,

Tel Aviv University, Ramat Aviv, Tel Aviv 69978, Israel

W. Francke

Institut für Organische Chemie, Universität Hamburg,

Martin-Luther-King Platz 6, 20146 Hamburg, Germany

X. Cerdá · R. Boulay

Estación Biológica de Doñana, CSIC,

Avda Americo Vespucio, 41092 Seville, Spain

R. Boulay

Departamento de Biología Animal,

Universidad de Granada, 18071 Granada, Spain
Keywords Aphaenogaster senilis .

Aphaenogaster iberica · Trail pheromone ·

Dufour's gland · Poison gland · Alkaloids · Hydrocarbons

\section{Introduction}

Recruitment is a key process in ant foraging activity, in which a worker, having encountered a valuable food source, communicates its location to nestmates to enhance the efficiency of food exploitation. The great diversity of recruitment modalities has been classified into three main categories by Wilson (1971): tandem running [e.g. in Temnothorax albipennis (Franks and Richardson 2006)], in which nestmates are recruited individually; group recruitment [e.g. in Camponotus cruentatus (Boulay et al. 2007a) or Aphaenogaster senilis (Cerdá et al. 2009)], in which a recruiter leads a small group of nestmates to the food source; and mass recruitment, in which a large number of individuals are mobilized to dominate an important food source [for a recent review and discussion see Dornhaus and Powell (2010)].

Chemical signals, often coupled with behavioural displays, are an important component of all the above recruitment modalities. These can be deposited by the recruiting ant either upon her return from the source to the nest (mass recruitment) or whilst she is leading her nestmates from the nest to the source (tandem running and group recruitment). These pheromones generally have a dual effect on the recruited ants, both triggering them to exit the nest and orienting them towards the resource. Trail-laying pheromones are chemically very diverse, produced by a plethora of glands, and have been identified in several ant species (Morgan 2009).

In the present laboratory study, we analysed the traillaying behaviour of foragers of A. senilis and the closely 
related species, A. iberica. We also examined whether Dufour's gland and the poison gland, which are considered to be the putative origin of trail pheromones in other Aphaenogaster species (Attygalle et al. 1998), are also the glandular source in the two species studied here. We analysed the chemistry and species specificity of trailfollowing pheromones of both species.

\section{Materials and methods}

Ant collection and maintenance in the laboratory

We collected four colonies of A. senilis and four colonies of A. iberica from the Parque Nacional de Doñana (Las Beles, $36^{\circ} 58^{0} 53^{00} \mathrm{~N}, 6^{\circ} 29^{0} 11^{00} \mathrm{~W}$, Huelva Province, Spain) and Parque Natural de la Sierra d'Espadá (Naquera, $3^{\circ} 39^{0} 27^{00} \mathrm{~N}, 0^{\circ} 25^{\circ} 32^{00} \mathrm{~W}$, Valencia Province, Spain), respectively. All colonies had a queen and abundant brood. They were maintained in artificial nests composed of a plastic box (29 $92799 \mathrm{~cm}$ ) containing two to three $2092 \mathrm{~cm}$ test tubes half-filled with water. Each nest was connected through a plastic tube to a large foraging arena (340 $95898 \mathrm{~cm}$ ), the edges of which were coated with fluon ${ }^{\circledR}$. A feeder was located in this arena at $2 \mathrm{~m}$ from the nest entrance, where food (mealworms and honey) was deposited twice a week ad libitum. The room temperature was maintained at $25 \pm 1^{\circ} \mathrm{C}$ on a 12:12 LD regime. All experiments were performed between 9:00 and 16:00 h, during the natural activity period of the ants.

Glandular origin of the trail pheromones in A. senilis and A. iberica

A classical bioassay was used to determine the glandular origin and species specificity of the trail-laying pheromones (Moser and Blum 1963; Lenoir et al. 1992); discussion in (Morgan 2009). A paper sheet (21 $929.7 \mathrm{~cm}$ ), on which a 20-cm long line had been drawn with a pencil, was placed on the floor of the foraging arena. All the extracts were prepared from randomly chosen ants in the foraging arena that were killed by freezing at $-20^{\circ} \mathrm{C}$ for $10 \mathrm{~min}$.

We pooled 20 heads, thoraces (plus legs) or abdomen in $1 \mathrm{ml}$ of pentane. For glandular extracts, glands were excised in distilled water. Twenty glands were pooled in $1 \mathrm{ml}$ of pentane; $50 \mathrm{ll}$ of extract (equivalent to one ant content) in pentane or pentane alone (control) was deposited along the line. After a delay of $20 \mathrm{~s}$ (solvent evaporation), the ants that followed the artificial trail for at least $2 \mathrm{~cm}$ were recorded for $3 \mathrm{~min}$. Controls with pentane were performed in random sequences with the test material throughout the experiments for all colonies. All the experiments were repeated $12-15$ times, with no more than two repetitions on the same day using the same colony.

In a first series of experiments, we tested trail-following behaviour using extracts of head, thorax (?legs) or abdomens of A. senilis. Subsequently, extracts of Dufour's gland or the poison gland were tested separately or in concert for both species. We also examined whether crossreactivity existed between the trails of both species.

\section{Chemical analyses}

For chemical analyses, we used extracts of 20 glands in $50 \mathrm{ll}$ pentane, of which $2 \mathbf{1 l}$ was injected into a Perkin Elmer GC/MS operating at $70 \mathrm{eV}$. Separations were achieved using a DB-5 fused silica capillary column, temperature programmed from $50^{\circ} \mathrm{C}$ (2 min hold) to $300^{\circ} \mathrm{C}$ at $6^{\circ} \mathrm{C} / \mathrm{min}$, and held at $300^{\circ} \mathrm{C}$ for the last $10 \mathrm{~min}$. A second set of analyses was carried out using an HP6890 gas chromatograph (Agilent) linked to a mass spectrometer VG70/250 SE (Vacuum Generators). Volatiles were separated with a $30 \mathrm{~m} 90.25 \mathrm{~mm}$ fused silica capillary BPX5 (SGE) that was temperature programmed from $60^{\circ} \mathrm{C}$ (3 min hold) to $280^{\circ} \mathrm{C}$ at $5^{\circ} \mathrm{C} / \mathrm{min}$.

We also analysed glands of ants collected from other areas in Spain to determine any possible geographical variations in gland contents.

\section{Statistics}

The numbers of ants that followed the artificial trails were compared between treatments by Kruskall-Wallis and Mann-Whitney tests. We used hierarchical cluster analysis (Euclidian distance, Ward method) for comparing the glandular chemical profiles, and Mann-Whitney test to compare the different categories (alkanes, alkenes and alkaloids) and groups of C15-, C17-, C19-hydrocarbons of the glandular contents.

\section{Results}

Glandular origin of the trail pheromones in A. senilis and A. iberica

Significantly more workers of A. senilis followed abdominal extracts as compared to extracts of either head or thorax or the pentane control $(10.93 \pm 3.46,4.73 \pm 2.23$, $1.63 \pm 1.07$ mean $\pm \mathrm{SD}$, respectively; Kruskall-Wallis $\mathrm{P} \backslash 0.05)$. This clearly indicated that the trail-following pheromone was produced or stored in the abdominal glands. Although we did not test this specifically, we 
hypothesized that A. iberica likewise utilizes its abdominal glands for trail marking.

Workers of A. senilis followed an artificial trail made of extracts of either Dufour's gland or the poison gland of conspecifics in larger numbers as compared to those following the pentane control (Fig. 1a). There was no synergistic effect when both glandular extracts were co-deposited as a trail. Cross-experiments showed that A. senilis ants did not follow trails prepared from A. iberica glands.

Figure $1 \mathrm{~b}$ shows that A. iberica workers followed marked trails irrespective of their glandular origin or whether they were prepared from conspecific or heterospecific ants. Notably, the overall trail following of A. iberica workers was much weaker (at $40 \%$ level) as compared to workers of A. senilis (see Fig. 1a).
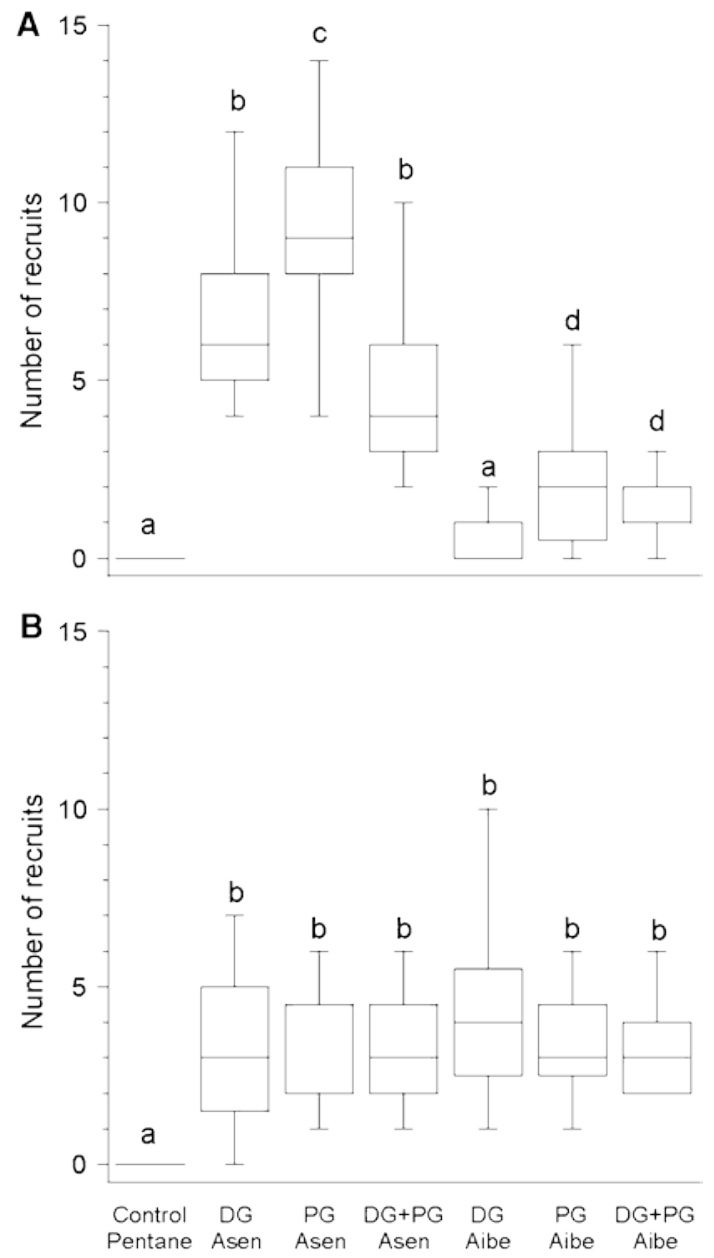

Fig. 1 Box plot showing the number of ants following an artificial trail made with DG Dufour gland, PG poison gland or DG ? PG of Asen (A. senilis) or Aibe (A. iberica). a Responses of A. senilis, b responses of A. iberica. Different letters indicate significant differences with Mann-Whitney U test
Chemical composition of Dufour's gland and poison gland secretions

The chemical composition of volatiles contained in Dufour's gland and in the poison gland of both species is given in Table 1. Dufour's gland secretions mainly comprised straight chain hydrocarbons with uneven numbers of carbons. Alkenes dominated in both species (60-70\%), whilst the ratios between alkenes and alkanes was similar (Mann-Whitney test, $\mathrm{P}=0.40$ for alkenes and $\mathrm{P}=0.30$ for alkanes). Nonetheless, the profiles of the two species differed: in A. senilis amounts of C15-, C17- and C19hydrocarbons were about $20-35 \%$ of the total amount of volatiles, confirming previous results (Boulay et al. 2007a), whereas in A. iberica C17-hydrocarbons constituted the major components (60\%), with $\backslash 5 \%$ of C19-homologues. Differences between the hydrocarbon patterns were found to be significant between the two species (Mann-Whitney test, $\mathrm{P}=0.05$ for $\mathrm{C} 15, \mathrm{P} \backslash 0.001$ for $\mathrm{C} 17$ and $\mathrm{P} \backslash 0.001$ for C19 groups), which was well represented in the dendrogram resulting from cluster analysis. There were no intraspecific differences related to geographic locations including Tenerife Island (Fig. 2a).

The poison gland of A. senilis workers was found to be a "bomb" of alkaloids containing a total of about $85-98 \%$ in some glands. The main alkaloid was anabaseine (3,4,5,6tetrahydro-2, $3^{0}$-bipyridine), which represented about twothirds of the glandular content. Anabaseine was accompanied by minor amounts of other alkaloids including anabasine, 2,3-bipyridine, and several as yet unidentified alkaloids. The alkaloids were accompanied by small amounts of alkanes (7\%) and alkenes (6\%). In very old workers, the glandular content changed considerably in colour and volume (Ichinose and Lenoir 2009), but we did not investigate whether this reflected changes in the chemistry. Surprisingly, the poison glands of A. iberica contained no alkaloids, but were mainly composed of hydrocarbons, the pattern of which resembled that of Dufour's gland. Accordingly, the two species readily separated as two clusters in the dendrogram, again without differences within the species along geographic locations (Fig. 2b).

\section{Discussion}

Our experiments with artificial trails indicate the gaster to be the source of the pheromone. In various Aphaenogaster species, the poison gland is the source of the trail pheromone, whereas Dufour's gland elicits no noticeable response (Attygalle et al. 1998). Both A. senilis and A. iberica seem to diverge from this scheme since they equally followed extracts of the two abdominal glands. The 
Table 1 Relative amounts (mean \pm SE) of the content of Dufour's gland (DG) and poison gland (PG) of A. senilis (A. seni) and A. iberica (A. iber)

\begin{tabular}{|c|c|c|c|c|}
\hline Name & DG A. seni $(n=6)$ & DG A. iber $(n=15)$ & PG A. seni $(n=20)$ & PG A. iber $(n=12)$ \\
\hline C10 & nd & nd & 1 & 3 \\
\hline Limonene & nd & nd & nd & 4 \\
\hline Nonanal & 3 & 3 & nd & 4 \\
\hline C11 & 1 & 2 & 1 & 5 \\
\hline Decanal & nd & 2 & nd & 2 \\
\hline C12:1 & nd & nd & nd & 3 \\
\hline C12 & 1 & $2-3$ & 2 & 4 \\
\hline C13:1a & 1 & 1 & nd & nd \\
\hline C13:1b & 2 & 2 & nd & nd \\
\hline C13 & 3 & 3 & 2 & 4 \\
\hline 5MeC13 & 1 & 1 & nd & 2 \\
\hline 3МеC13 & 2 & 2 & nd & 1 \\
\hline C14:1 & 3 & 2 & nd & 1 \\
\hline C14 & 3 & 4 & 3 & 6 \\
\hline Anabasine & nd & nd & 4 & nd \\
\hline Alkaloid $^{\mathrm{a}}$ & nd & nd & 6 & nd \\
\hline C15:2 & 2 & $2-3$ & nd & nd \\
\hline C15:1 a & 4 & 5 & 1 & 4 \\
\hline a-Farnesene & 1 & nd & nd & nd \\
\hline C15:1 b & 8 & 4 & nd & nd \\
\hline C15 & $7-8$ & $7-8$ & 4 & 7 \\
\hline 2,30-Bipyridine & nd & nd & 3 & nd \\
\hline Anabaseine & nd & nd & 9 & nd \\
\hline 7MeC15 & $1-2$ & 1 & nd & nd \\
\hline 5MeC15 & 3 & 1 & nd & nd \\
\hline 3МeC15 & $3-4$ & 1 & nd & nd \\
\hline C16:1a & 2 & 3 & nd & 4 \\
\hline Alkaloid $^{\mathrm{a}}$ & nd & nd & 6 & nd \\
\hline C16:1 b & 1 & 4 & nd & nd \\
\hline Tetradecanal & 1 & 1 & nd & nd \\
\hline C16 & 3 & 3 & 3 & 4 \\
\hline Alkaloid $^{\mathrm{a}}$ & nd & nd & $5-6$ & nd \\
\hline 4MeC16 & 2 & 2 & nd & nd \\
\hline $\mathrm{C} 17: 2 \mathrm{a}$ & 4 & 3 & $2-3$ & $6-7$ \\
\hline $\mathrm{C} 17: 2 \mathrm{~b}$ & 4 & 8 & nd & nd \\
\hline C17:1 a & 5 & 9 & 2 & 8 \\
\hline C17:1 b & 3 & 2 & 1 & nd \\
\hline C17 & 6 & 4 & 3 & 5 \\
\hline 9 ? 7MeC17 & 1 & 1 & nd & nd \\
\hline Alkaloid $^{\mathrm{a}}$ & nd & nd & 1 & nd \\
\hline 5MeC17 & 2 & 1 & nd & nd \\
\hline C18:2 & 2 & 1 & nd & nd \\
\hline C18:1 a & 3 & 2 & 1 & 3 \\
\hline C18:1 b & 2 & nd & nd & nd \\
\hline Pentadecenal & 2 & 1 & nd & nd \\
\hline C18 & 3 & 3 & $1-2$ & 4 \\
\hline 4 ? 8MeC18 & 2 & 1 & nd & nd \\
\hline Hexadecanal & 1 & nd & nd & nd \\
\hline
\end{tabular}


Table 1 continued

\begin{tabular}{lllll}
\hline Name & DG A. seni $(\mathrm{n}=6)$ & DG A. iber $(\mathrm{n}=15)$ & PG A. seni $(\mathrm{n}=20)$ & PG A. iber $(\mathrm{n}=12)$ \\
\hline C19:2 a & 3 & nd & $3-4$ & $3-4$ \\
C19:2 b & $7-8$ & 2 & nd & nd \\
C19:1 & 8 & 4 & 4 & $4-5$ \\
C19 & $2-3$ & 3 & 2 & 5 \\
9 MeC19 & 2 & nd & nd & nd
\end{tabular}

C12:1, dodecene; C15:2, pentadecadiene; 5MeC13, 5-methyltridecane, etc.

Not detected $=$ nd, $0.01-0.09 \%=1,0.10-0.49 \%=2,0.50-1.49 \%=3,1.5-3.9 \%=4,4.0-5.9 \%=5,6.0-9.9 \%=6,10.0-14.9 \%=7$, $15.0-20.0 \%=8$, more than $20 \%=9$

${ }^{a}$ Compound with unknown structure but uneven molecular weight
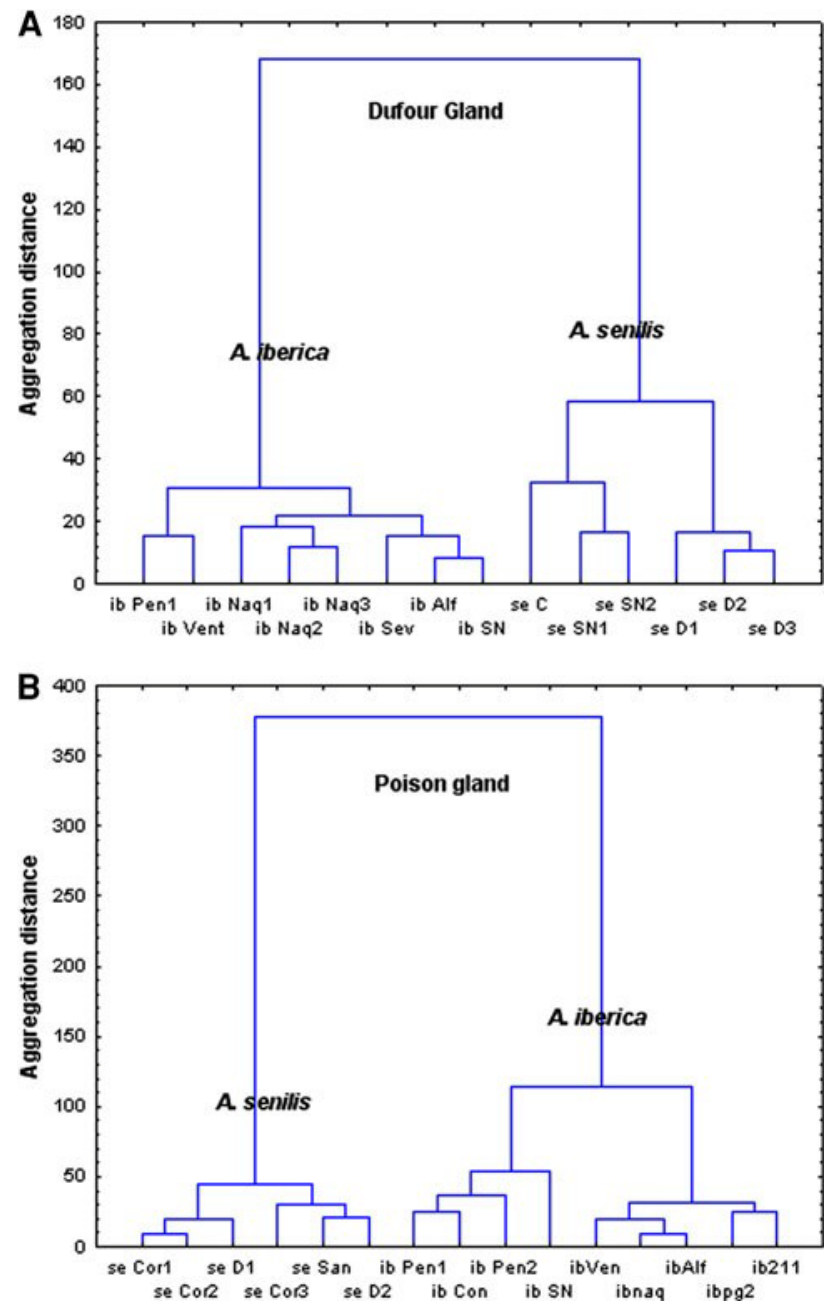

Fig. 2 Dendrogram of Dufour glands (a) and poison glands (b) of A. senilis and A. iberica (hierarchical cluster analysis, Ward method, Euclidian distances). Each point is one colony (1 sample or the mean of 2-6 extracts). Pen Parque Natural da Peneda-Gerês (Portugal), Naq Parque Natural de la Sierra d'Espadá, Naquera (Valencia, Spain), Alf Alfajarin (Zaragoza, Spain), C Canaries (Tenerife Island, Spain), Andalusia (southern Spain): SN Sierra Nevada, Sev Sevilla, Cor Coria del Rio, San Sanlucar de Barrameda, D Parque Nacional de Doñana, Las Beles, Con Constantina, Ven Venta two species differ, however, in their trail specificity. A. senilis followed only trails deposited by extracts of conspecifics, whilst A. iberica followed artificial trails made from extracts of both conspecifics and heterospecifics. The greater response of A. senilis to artificial trails is intriguing. It is possible that the alkaloids in the poison gland act as a stimulating agent, resulting in more intensive recruitment. Alkaloids were also reported to compose the trail pheromone of A. rudis (Attygalle et al. 1998). In the poison gland of the two species studied here, we could not detect 4-methyl-3-heptanone or 1-phenylethanol, which have been reported to serve as permanent trail pheromones in Aphaenogaster albisetosa and A. cockerelli (Hölldobler et al. 1995). These species were previously classified within the genus Novomessor and, therefore, may represent different lineages within the genus Aphaenogaster.

The less efficient trail-following exhibited by A. iberica workers suggests a less efficient recruitment system, in line with the fact that this species has different life traits. Colonies of A. senilis contain between 200 and 3,000 workers (Ledoux 1971; Boulay et al. 2007b, 2009), whereas A. iberica colonies are composed of smaller colonies (522 \pm 69 workers, $\mathrm{N}=12$ colonies, R. Boulay unpublished data) and have a much smaller area of distribution, which is limited to the more xeric habitats in the Iberian Peninsula (Espadaler and Riasol 1983) where pheromone trails evaporate more rapidly (Ruano et al. 2000). On rare occasions, both species can be sympatric and may compete for similar resources, including insect corpses, vegetal debris and seeds. Furthermore, the lack of trail-following specificity shown by A. iberica lends credence to it being an inefficient recruiter that is somewhat able to follow short distances of any trail made of hydrocarbons. We verified that the observed differences in trail following are not due to differences in gland size.

The poison gland of A. senilis is composed mostly of the alkaloid anabaseine, accompanied by small amounts of anabasine and other alkaloids, whilst in A. iberica this 
gland contains only hydrocarbons. Our data on A. senilis confirm the presence of anabaseine as the major product of the poison gland (Leclercq et al. 2001). Anabasine and anabaseine have been found in some Aphaenogaster species and in the close genus Messor (Coll et al. 1987; Brand and Mpura 1993; Jackson et al. 1989; Leclercq et al. 2001; Cruz-Lopez et al. 2004); however, these alkaloids are sometimes absent, which can be of taxonomic significance [see reviews by Braekman et al. (1998); Morgan (2008), (2009)]. They are present in all Aphaenogaster species sensu stricto where they have been sought, such as A. rudis (Attygalle et al. 1998), A. fulva and A. tennesseensis (Wheeler et al. 1981), A. subterranea and A. miamiana (Leclercq et al. 2001). The disparity in alkaloid production between the two closely related species, A. senilis and A. iberica, raises an evolutionary question as to the selective pressures that may have induced strong chemical differences in the poison gland chemistry, but not in that of Dufour's gland. Investigations on the ecological significance of the alkaloids of $\mathrm{A}$. senilis will be the subject of future work.

Acknowledgments We thank Servane Merlet and Marie Bailleau for help with the experiments, Jean-Philippe Christidès for the chromatography, Guy Bourdais for rearing the ants, the authorities of the Doñana National Park for the permit to collect the ants, and Fernando Amor for samples from Canaries. This research was conducted with an ECODOCA (European Commission FP5-Access to Research Infrastructure action of the Improving Human Potential Program in Doñana Biological Station) project no. 9/2003 to A.L. We thank Naomi Paz for editorial assistance.

\section{References}

Attygalle AB, Kern F, Huang Q, Meinwald J (1998) Trail pheromone of the myrmicine ant Aphaenogaster rudis (Hymenoptera: Formicidae). Naturwissenschaften 85:38-41

Boulay R, Cerdá X, Simon T, Roldan M, Hefetz A (2007a) Intraspecific competition in the ant Camponotus cruentatus: should we expect the 'dear enemy’ effect? Anim Behav 74:985-993

Boulay R, Hefetz A, Cerdá X, Devers S, Francke W, Twele R, Lenoir A (2007b) Production of sexuals in a fission-performing ant: dual effects of queen pheromone and colony size. Behav Ecol Sociobiol 61:1531-1541

Boulay R, Cerdá X, Fertin A, Ichinose K, Lenoir A (2009) Brood development into sexual females depends on the presence of a queen but not on temperature in an ant dispersing by colony fission, Aphaenogaster senilis. Ecol Entomol 34:595-602. doi: 10.1111/j.1365-2311.2009.01108.x
Braekman J-C, Daloze D, Pasteels J (1998) Alkaloids in animals. In: Roberts and Wink (eds) Biochemistry, ecology and medical applications. Plenum Press. New York, pp 349-378

Brand JM, Mpuru SP (1993) Dufour's gland and poison gland chemistry of the myrmicine ant, Messor capensis (Mayr). J Chem Ecol 19:1315-1320

Cerdá X, Angulo E, Boulay R, Lenoir A (2009) Individual and collective foraging decisions: a field study of worker recruitment in the gypsy ant Aphaenogaster senilis. Behav Ecol Sociobiol 63:551-562

Coll M, Hefetz A, Lloyd HA (1987) Adnexal gland chemistry of Messor ebeninus Forel (Formicidae: Myrmicinae). Zeitschrift für Naturforschung Section C Biosciences 42:1027-1029

Dornhaus A, Powell S (2010) Foraging and defence strategies. In: Lach L, Parr CL, Abbott KL (eds) Ant ecology. Oxford University Press, Oxford, pp 210-230

Espadaler X, Riasol JM (1983) Distribución, variabilidad y sinonimias en Aphaenogaster ibérica [sic] Emery, 1908 y dos adiciones a la fauna ibérica (Hymenoptera, Formicidae). In: Actas del I Congreso Ibérico de Entomología, vol 1(1). Universidad de León, León, pp 219-228

Franks NR, Richardson T (2006) Teaching in tandem-running ants. Nature 439:153

Hölldobler B, Oldham NJ, Morgan ED, König WA (1995) Recruitment pheromones in the ants Aphaenogaster albisetosus and A.cockerelli (Hymenoptera: Formicidae). J Insect Physiol 41:739-744

Ichinose K, Lenoir A (2009) Reproductive conflict between laying workers in the ant Aphaenogaster senilis. J Ethol 27:475-481

Jackson BD, Wright PJ, Morgan ED (1989) 3-Ethyl-2,5-dimethylpyrazine, a component of the trail pheromone of the ant Messor bouvieri. Experientia 45:487-489

Leclercq S, Charles S, Daloze D, Braekman J-C, Aron S, Pasteels JM (2001) Absolute configuration of anabasine from Messor and Aphaenogaster ants. J Chem Ecol 27:945-952. doi:10.1023/ A:1010335003297

Ledoux A (1971) Un nouveau mode de bouturage de société chez la fourmi Aphaenogaster senilis Mayr. C R Acad Sci Paris 273D:83-85

Lenoir A, Detrain C, Barbazanges N (1992) Host trail following by the guest ant Formicoxenus provancheri. Experientia 48:94-97

Morgan ED (2008) Chemical sorcery for sociality: exocrine secretions of ants (Hymenoptera: Formicidae). Myrmecol News 11:79-90

Morgan ED (2009) Trail pheromones of ants. Physiol Entomol 34: 1-17. ISI: 000263329600001

Moser JC, Blum MS (1963) Trail marking substance of the Texas leaf-cutting ant: source and potency. Science 140:1228

Ruano F, Tinaut A, Soler JJ (2000) High surface temperatures select for individual foraging in ants. Behav Ecol 11:396-404

Wheeler JW, Olubajo O, Storm CB, Duffield RM (1981) Anabaseine: venom alkaloid of Aphaenogaster ants attractants. Science 211:1051-1052

Wilson EO (1971) The insect societies. Harvard University Press, Cambridge 